\title{
Effect of Parasitic Element on 408 MHz Antenna for Radio Astronomy Application
}

\author{
Radial Anwar, ${ }^{1}$ Mohammad Tariqul Islam, ${ }^{2}$ Norbahiah Misran, ${ }^{1,2}$ Geri Gopir, ${ }^{1,3}$ \\ Baharudin Yatim, ${ }^{1,3}$ and Mhd Fairos Asillam ${ }^{4}$ \\ ${ }^{1}$ Institute of Space Science, Universiti Kebangsaan Malaysia, 43600 Bangi, Selangor, Malaysia \\ ${ }^{2}$ Department of Electrical, Electronic and Systems Engineering, Faculty of Engineering and Built Environment, Universiti Kebangsaan \\ Malaysia, 43600 Bangi, Selangor, Malaysia \\ ${ }^{3}$ School of Applied Physics, Faculty of Science and Technology, Universiti Kebangsaan Malaysia, 43600 Bangi, Selangor, Malaysia \\ ${ }^{4}$ National Space Agency of Malaysia, Lot 2233, Kg. Sungai Lang, 42700 Banting, Selangor, Malaysia
}

Correspondence should be addressed to Radial Anwar; adi_astro@yahoo.com

Received 13 November 2013; Accepted 28 January 2014; Published 10 April 2014

Academic Editor: Rezaul Azim

Copyright ( 2014 Radial Anwar et al. This is an open access article distributed under the Creative Commons Attribution License, which permits unrestricted use, distribution, and reproduction in any medium, provided the original work is properly cited.

Antenna is one of the important subsystem components in a radio telescope system. In this paper, analysis on the effect of parasitic element on $408 \mathrm{MHz}$ antenna in a radio telescope system is presented. Higher gain up to $10.24 \mathrm{dBi}$ with reduction on beamwidth size has been achieved by optimizing the position of parasitic element relative to the driven element. The proposed antenna is suitable to be utilized in a transient radio telescope array.

\section{Introduction}

Observation at radio wavelength has become a great scientific and applied importance in the field of astronomy. Many new types of astronomical object have been discovered by radio astronomical methods, including quasars, pulsars, and cosmic microwave background (CMB). This development has intrigued deep exploration in the field of radio astrophysics and computation and in the radio astronomical instrumentation.

In the field of instrumentation, the antenna becomes one of the vital and most explored fields of research [1-3]. As for radio astronomy application, antennas also have been developed in various manners based on the objectives of the observation. It plays an important role in determining the sky coverage (field of view) and angular resolution, as well as affecting the overall sensitivity of the radio telescope. Most of the radio telescope system employs a dish antenna as it inherits a very high angular resolution and gain [4]. However, for low-frequency observation (decimeter, meter, and decameter wavelength), the size of the dish antenna becomes impractically large, leading to complex construction and maintenance problems as well as high cost factor. Hence, dipole-based antenna has become a more suitable option for long-wave radio astronomy observation. Radio JOVE by NASA [5], the low frequency array (LOFAR) [6], and the eight-meter-wavelength transient array (ETA) radio telescope at Pisgah Astronomical Research Institute (PARI) $[7,8]$ are among the radio telescope systems which utilized dipole-based antenna.

One of the common methods in utilizing the dipolebased antenna is by constructing it in inverted-V-shape, as it provides low mismatch at the terminal point for $50 \mathrm{ohms}$ transmission line and wide beamwidth (sky coverage) [68]. It is utilized in large array system where high angular resolution can be obtained by applying the aperture synthesis technique and hence is suitable to substitute the large dish antenna. Another method is by utilizing parasitic element to increase the gain of the antenna $[9,10]$ and hence it increases the sensitivity of the radio telescope system. This method is suitable when the sky coverage is less important than the sensitivity. In this paper, effect of parasitic element on a $408 \mathrm{MHz}$ antenna is presented. The objective of this paper is to show the improvement on beamwidth which can 
be obtained by utilizing parasitic element in a dipole-based antenna. The method described in this paper also can be used to design antenna with different beamwidth and gain requirement at different frequencies. $408 \mathrm{MHz}$ is the centre of the $406 \mathrm{MHz}-410 \mathrm{MHz}$ band which is protected by ITU for radio astronomy observation [11]. Several potential objects to be observed at this frequency include the Sun and pulsars.

\section{Methodology}

The V-shape dipole-based antenna with parasitic element has been utilized in $[12,13]$. However, it was utilized for multiband antenna system which is operated at VHF region. The V-shape concept is chosen as it provides the opportunity to investigate the antenna properties (standing wave ratio (SWR), gain, and beamwidth) when it is placed very near to the ground.

The basic structure of the proposed antenna is shown in Figure 1. Three parameters of the driven element are varied to see the changes on the antenna performances. They are the length of the dipole arms $\left(L_{d}\right)$, angle of the V-shape driven element $(\theta)$, and the height of the feed point from the ground $(H)$. The angles are varied from $70^{\circ}$ to $180^{\circ}$ with $10^{\circ}$ steps, while the heights are varied at $\lambda / 4, \lambda / 5, \lambda / 6, \lambda / 7$, and $\lambda / 8$, where $\lambda$ is the wavelength that corresponds to $408 \mathrm{MHz}$ operating frequency, of about 0.735 meters. Hence, the lengths of the arms were optimized to be operated at $408 \mathrm{MHz}$ within 60 setups. Angles which are lower than $70^{\circ}$ are not investigated as theoretically they will inherit high standing wave ratio (SWR), while higher than $180^{\circ}$ means it already becomes an inverted-V-shape. The heights of $\lambda / 4$ to $\lambda / 8$ are chosen as it theoretically will provide the maximum gain achieved at zenith direction, a property which is important for an antenna to be employed in a radio telescope system.

The first setup is height of $\lambda / 4$, angle of $70^{\circ}$. With this setup, the length of the antenna arm is varied until the peak of SWR achieved around $408 \mathrm{MHz}$. Then, the beamwidth, gain, and SWR values for that setup are recorded. This procedure is repeated for all combination of angles and heights. Once the lowest SWR is obtained, a parasitic element is added in the structure and also undergoes optimization process. There are two parameters of the parasitic element which are investigated. They are the distance of the parasitic element from the feed point $(D)$ and the length of the parasitic element itself $\left(L_{p}\right)$. The distances are varied at $\lambda / 2, \lambda / 3, \lambda / 4$, and $\lambda / 5$, while the lengths are varied at $0.45 \lambda, 0.40 \lambda, 0.35 \lambda$, $0.30 \lambda$, and $0.25 \lambda$. From the obtained data, a structure which provides the most balance parameters, in sense of a good trade between SWR, gain, and beamwidth, is chosen as the proposed antenna.

\section{Results and Discussion}

The proposed antenna has been investigated by utilizing numerical electromagnetic code based software (NEC4WIN95VM). The simulations are conducted with perfect ground parameters and $50 \mathrm{ohms}$ impedance at

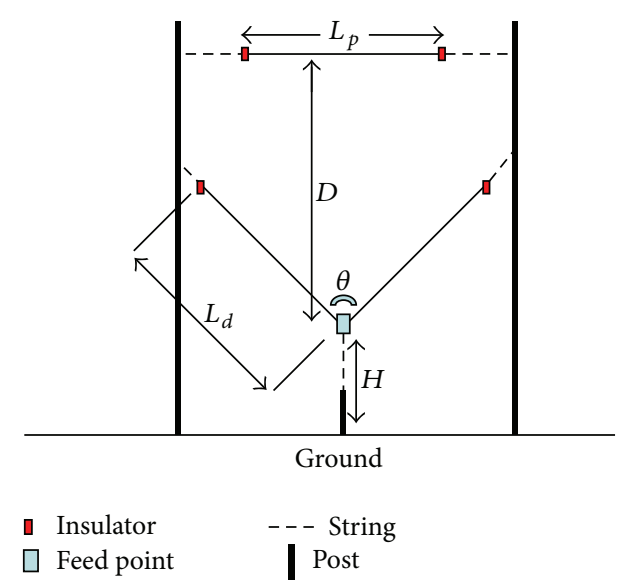

FIgURE 1: Geometry of the proposed antenna.

TABLE 1: Geometry of the proposed antenna.

\begin{tabular}{lc}
\hline Parameters & Values \\
\hline Half dipole arm $\left(L_{d}\right)$ & $168 \mathrm{~mm}$ \\
Height $(H)$ & $122 \mathrm{~mm}(\lambda / 6)$ \\
Parasitic element length $\left(L_{p}\right)$ & $294 \mathrm{~mm}(0.4 \lambda)$ \\
Parasitic element distance $(D)$ & $245 \mathrm{~mm}(\lambda / 3)$ \\
Angle $(\theta)$ & $130^{\circ}$ \\
\hline
\end{tabular}

the terminal point. Conductive wires with six millimeter of diameter are utilized to construct the design in the simulations.

Table 1 shows the geometry of the proposed antenna. The length of half dipole $\operatorname{arm}\left(L_{d}\right)$ is of about $168 \mathrm{~mm}$, with angle between the arms $(\theta)$ of about $130^{\circ}$. The feed point in the center of the driven element $(H)$ is of about $120 \mathrm{~mm}$ above the ground. The parasitic element is positioned at $245 \mathrm{~mm}$ above the feed point $(D)$ with length of $294 \mathrm{~mm}\left(L_{p}\right)$.

Figure 2 shows the variation of the antenna SWR over heights and angles between the arms. The lowest SWR has been obtained at height of $\lambda / 6$ and angle between the arms is $130^{\circ}$. The SWR value is 1.008 . In general, the SWR of an antenna is affected by its surrounding, in sense that any nearby object may potentially increase the antenna SWR. From the graph at Figure 2, it can be seen that the SWR is affected not only by the ground, but also by the arms of the antenna itself. This is shown by the high SWR when the angle between the arms is small. As the angle increases, the SWR became lower until it reaches a turning point where the lowest SWR is obtained. Then, the SWR increases again as the angle became bigger, and the surface of the antenna is more exposed to the ground. The effect of the ground is also pronounced when the height became lower, that the SWR become higher while maintaining its pattern similar to the pattern at the height of $\lambda / 6$. When the antenna is placed higher than $\lambda / 6$, the peak of SWR is obtained at smaller angles, probably due to the minimum effect from the ground and hence the SWR is only affected by the interaction between the arms of the antenna. 


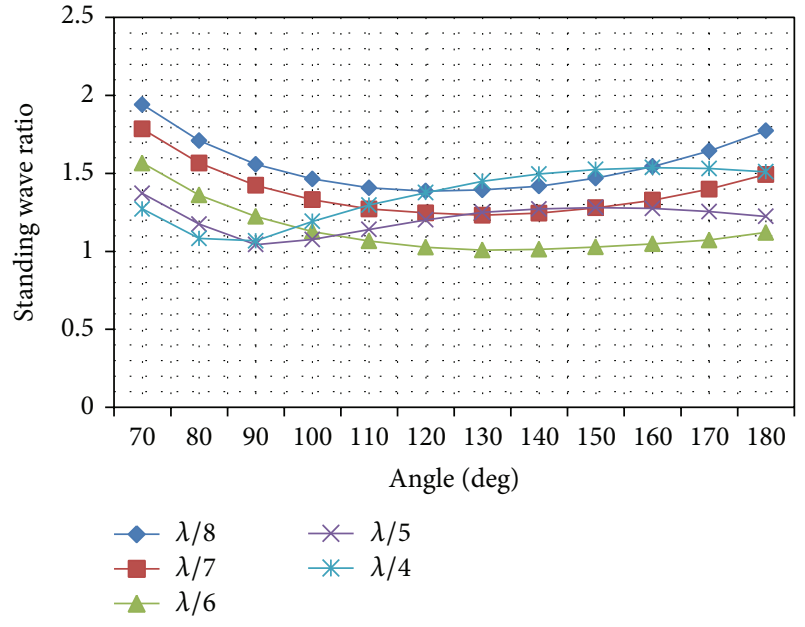

FIGURE 2: Variation of SWR for the V-shape driven element without parasitic element.

Variation of SWR, beamwidth, and gain of the V-shape antenna with a parasitic element are depicted in Figures 3, 4, and 5 , respectively. The length of parasitic element of $0.4 \lambda$ is chosen and the distance from feed point of $\lambda / 3$ is chosen as it provides a good trade-off, where the SWR is still relatively low, the beamwidth is small and the gain is high. From Figure 3, it can be seen that the effect of parasitic element to the $\mathrm{V}$-shape driven element diminishing as the length of the parasitic element become shorter and its distance from feed point become farther. It also should be noted that a relatively long parasitic element may shift the operating frequency of the antenna into lower frequency. For example, at the same distance of $\lambda / 3$, a $0.45 \lambda$ parasitic element will shift the peak of SWR into $401 \mathrm{MHz}$.

Form Figures 4 and 5, it can be seen that the length of parasitic element of $0.45 \lambda$ provides the smallest beamwidth and highest gain for the proposed antenna. However it is not selected due to the high SWR at this length. As the length decreases, effect of the parasitic element is also diminishing, shown by the wider beamwidth and lower gain. The distance of the parasitic element is also highly affecting the beamwidth and gain of the antenna, probably due to the difference of the phase of the incident signal at the driven element after alteration by the parasitic element. The closer the parasitic element is placed relative to the feed point, the faster its effect on beamwidth and gain diminishing as the length decreases.

Utilizing a parasitic element in the proposed antenna has significantly improved the beamwidth and gain of the antenna, with a higher SWR as a trade-off. Figure 6 shows comparison of the SWR when the proposed antenna before and after a parasitic element is utilized. The SWR of 1.008 increases into 1.652 when the parasitic element is utilized, which is still an acceptable SWR for an antenna to be employed in a radio telescope system. However the beamwidth is significantly reduced from $110^{\circ}$ without parasitic element into $70^{\circ}$ when a parasitic element is utilized, as depicted in Figure 7. It also can be seen that the gain is also improved from $8.18 \mathrm{dBi}$ without parasitic element

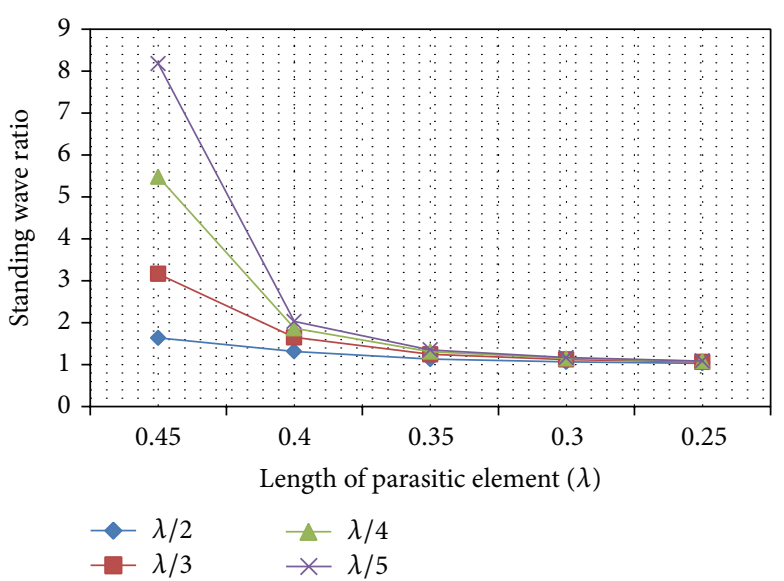

FIGURE 3: Variation of SWR for the V-shape driven element with a parasitic element.

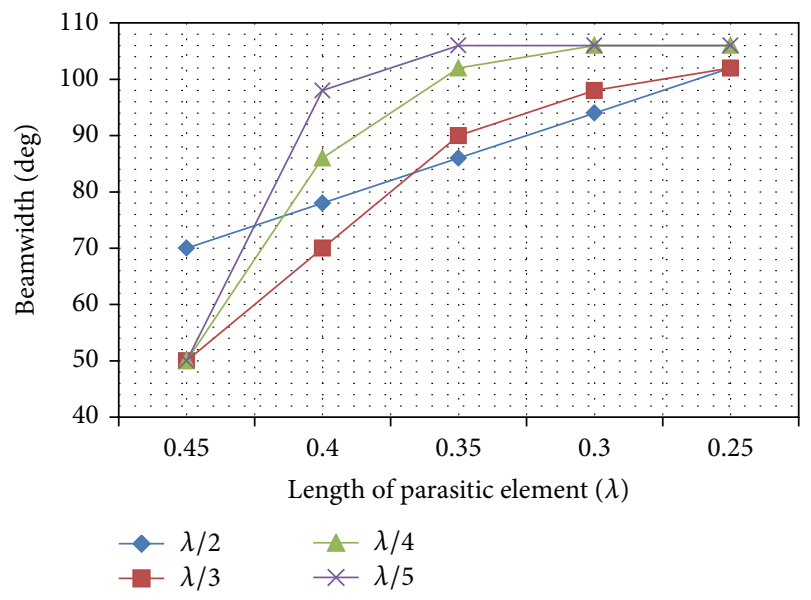

FIGURE 4: Variation of beamwidth for the V-shape driven element with a parasitic element.

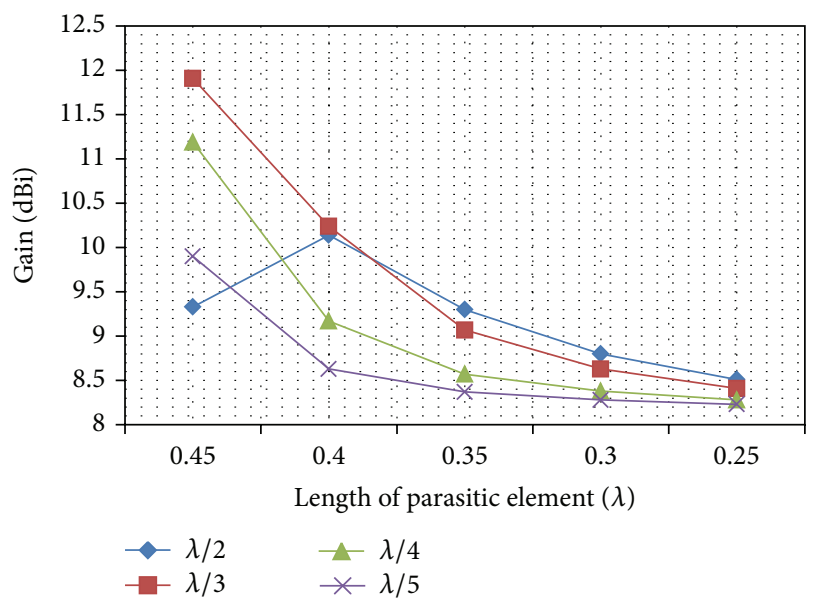

FIGURE 5: Variation of gain for the V-shape driven element with a parasitic element. 


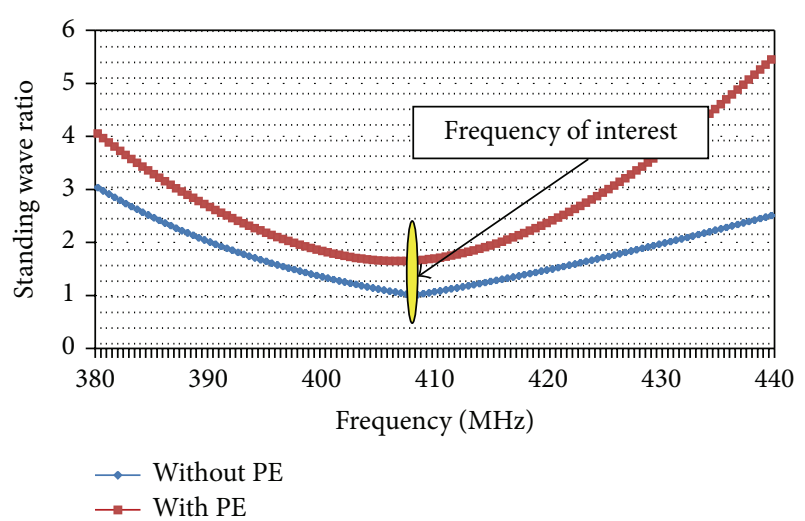

FIGURE 6: Comparison of SWR of the antenna with and without parasitic element $(\mathrm{PE})$.

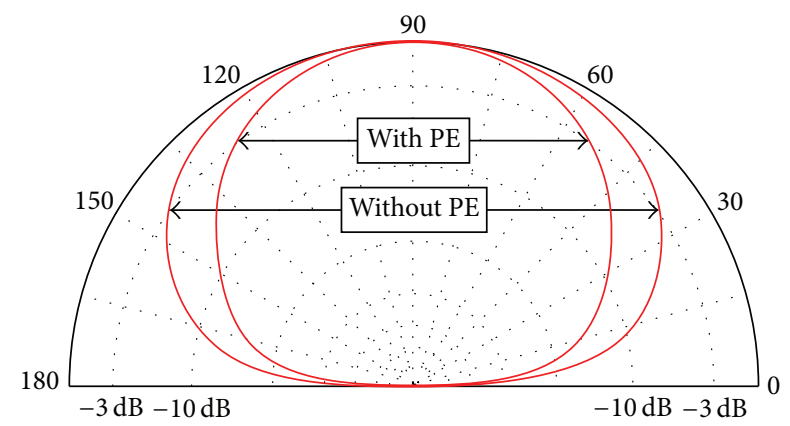

FIGURE 7: Comparison of beamwidth of the antenna with and without parasitic element (PE).

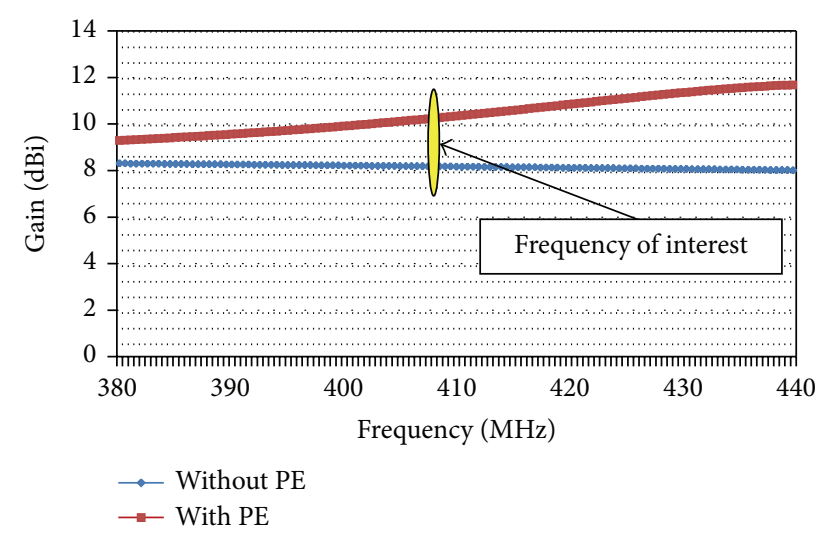

FIGURE 8: Comparison of gain of the antenna with and without parasitic element (PE).

into $10.24 \mathrm{dBi}$ with parasitic element. Figure 8 shows the comparison of the gain.

\section{Conclusion}

Effect of parasitic element on $408 \mathrm{MHz}$ antenna for a radio telescope system is analyzed in this paper. It has been shown that, by utilizing a parasitic element, beamwidth and gain of a dipole-based antenna can be increased significantly despite the raise on SWR value as a trade-off. A design of new antenna for a $408 \mathrm{MHz}$ radio telescope is also presented. The achieved result shows that the proposed antenna is suitable to be employed in a radio telescope system with tracking system where the sky coverage should not be too wide. The method described in this paper can be used to design antenna with different beamwidth and gain requirement at different frequencies.

\section{Conflict of Interests}

The authors declare that there is no conflict of interests regarding the publication of this paper.

\section{References}

[1] L. Liu, S. W. Cheung, R. Azim, and M. T. Islam, "A compact circular-ring antenna for ultra-wideband applications," Microwave and Optical Technology Letters, vol. 53, no. 10, pp. 2283-2288, 2011.

[2] R. Azim, M. T. Islam, J. S. Mandeep, and A. T. Mobashsher, "A planar circular ring ultra-wideband antenna with dual bandnotched characteristics," Journal of Electromagnetic Waves and Applications, vol. 26, no. 14-15, pp. 2022-2032, 2012.

[3] R. Azim, M. T. Islam, N. Misran, and A. T. Mobashsher, "Compact UWB planar antenna for broadband applications," Informacije MIDEM, vol. 41, no. 1, pp. 37-40, 2011.

[4] W. N. Christiansen and J. A. Högbom, Radiotelescopes, Cambridge University Press, Cambridge, UK, 2nd edition, 1985.

[5] http://radiojove.gsfc.nasa.gov/, 2009.

[6] M. De Vos, A. W. Gunst, and R. Nijboer, "The LOFAR telescope: system architecture and signal processing," Proceedings of the IEEE, vol. 97, no. 8, pp. 1431-1437, 2009.

[7] S. W. Ellingson, "Antennas for the next generation of lowfrequency radio telescopes," IEEE Transactions on Antennas and Propagation, vol. 53, no. 8, pp. 2480-2489, 2005.

[8] S. W. Ellingson, J. H. Simonetti, and C. D. Patterson, "Design and evaluation of an active antenna for a $29-47 \mathrm{MHz}$ radio telescope array," IEEE Transactions on Antennas and Propagation, vol. 55, no. 3, pp. 826-831, 2007.

[9] C. J. Panagamuwa, A. Chauraya, and J. C. Vardaxoglou, "Frequency and beam reconfigurable antenna using photoconducting switches," IEEE Transactions on Antennas and Propagation, vol. 54, no. 2, pp. 449-454, 2006.

[10] F. Fezai, C. Menudier, M. Thevenot, and T. Monediere, "Systematic design of parasitic element antennas-application to a WLAN Yagi design," IEEE Antennas and Wireless Propagation Letters, vol. 12, p. 413, 2013.

[11] CRAF (Committee on Radio Astronomy Frequencies), CRAF Handbook for Radio Astronomy, European Science Foundation, 3rd edition, 2005.

[12] R. Anwar, M. T. Islam, N. Misran, G. Gopir, and B. Yatim, "Development of a multiband VHF antenna for low-frequency transient radio telescope," Journal of Electromagnetic Waves and Application, vol. 23, pp. 1843-1854, 2009.

[13] R. Anwar, N. Misran, M. T. Islam, and G. Gopir, "Compact multiband VHF antenna for transient radio telescope," in Proceedings of the International Conference on Space Science and Communication, pp. 182-185, Malacca, Malaysia, October 2009. 

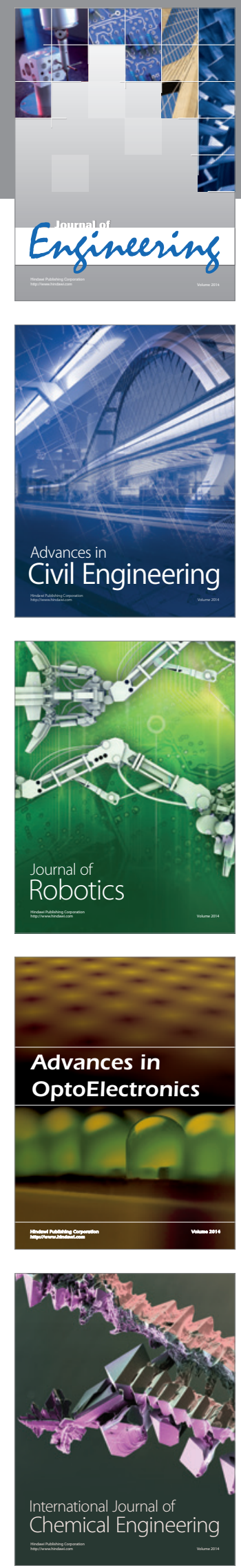

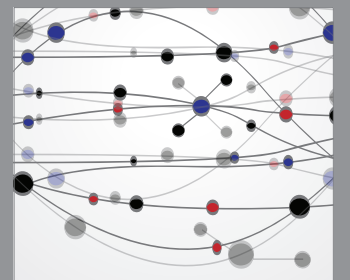

The Scientific World Journal
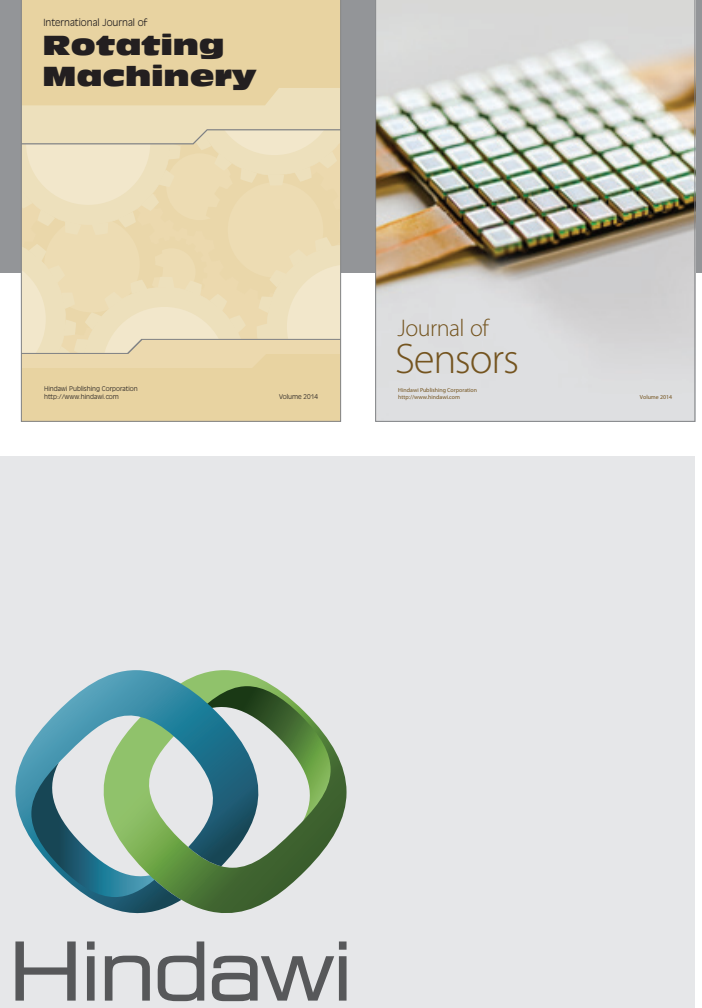

Submit your manuscripts at http://www.hindawi.com
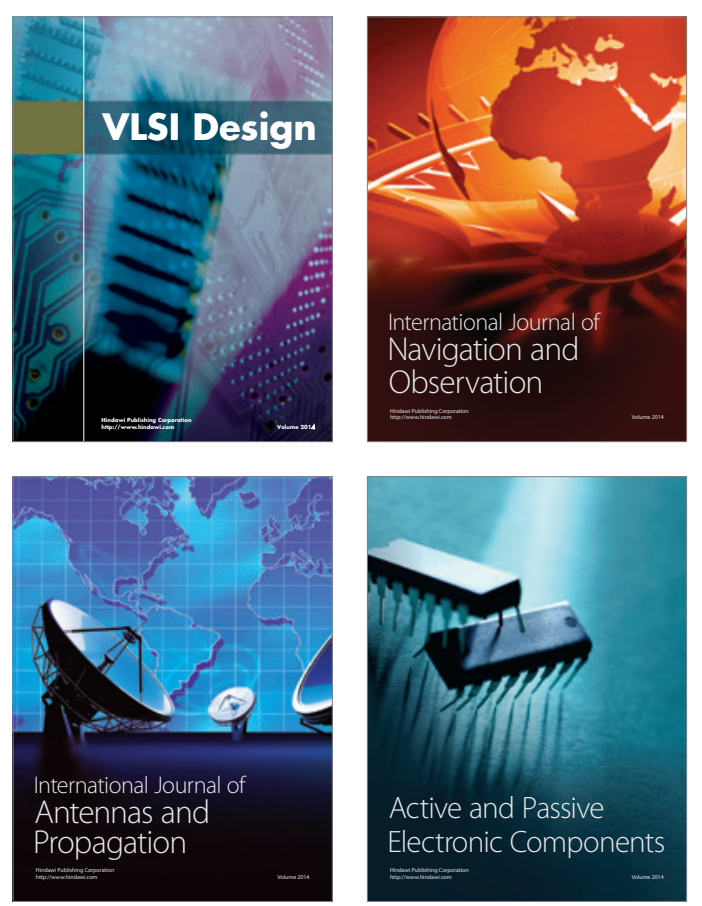
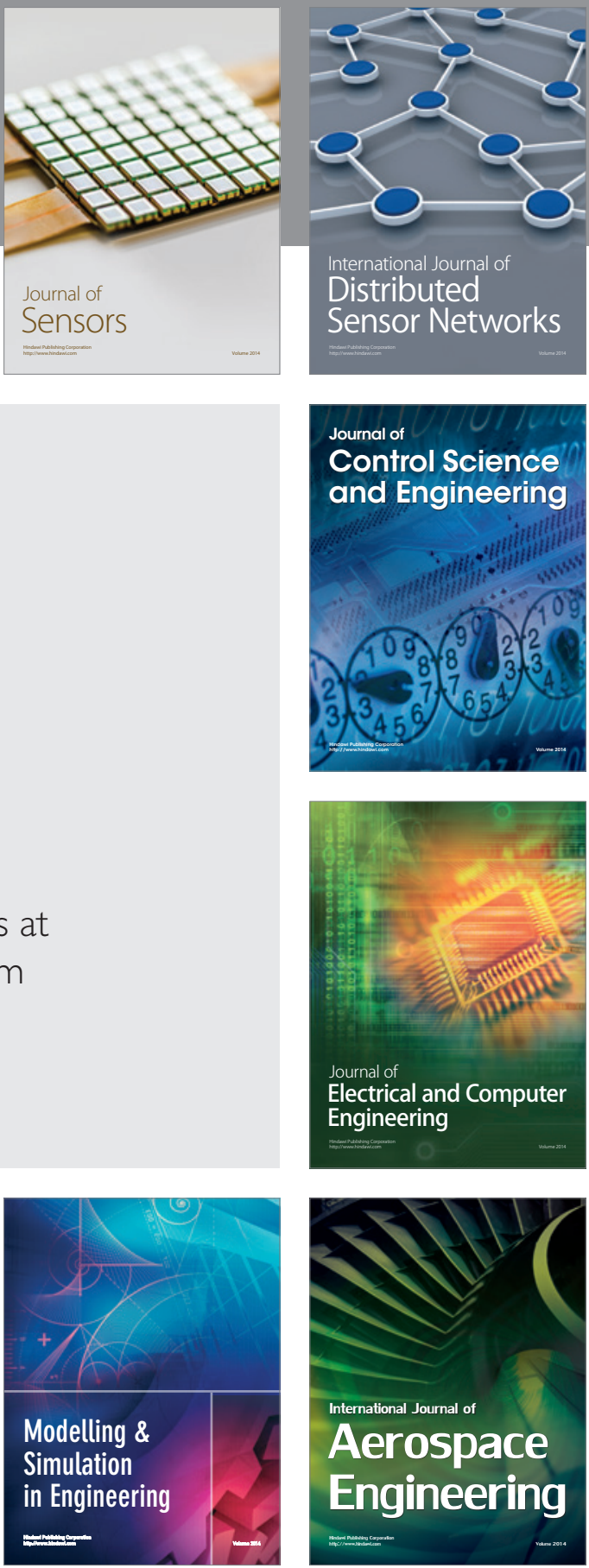

Journal of

Control Science

and Engineering
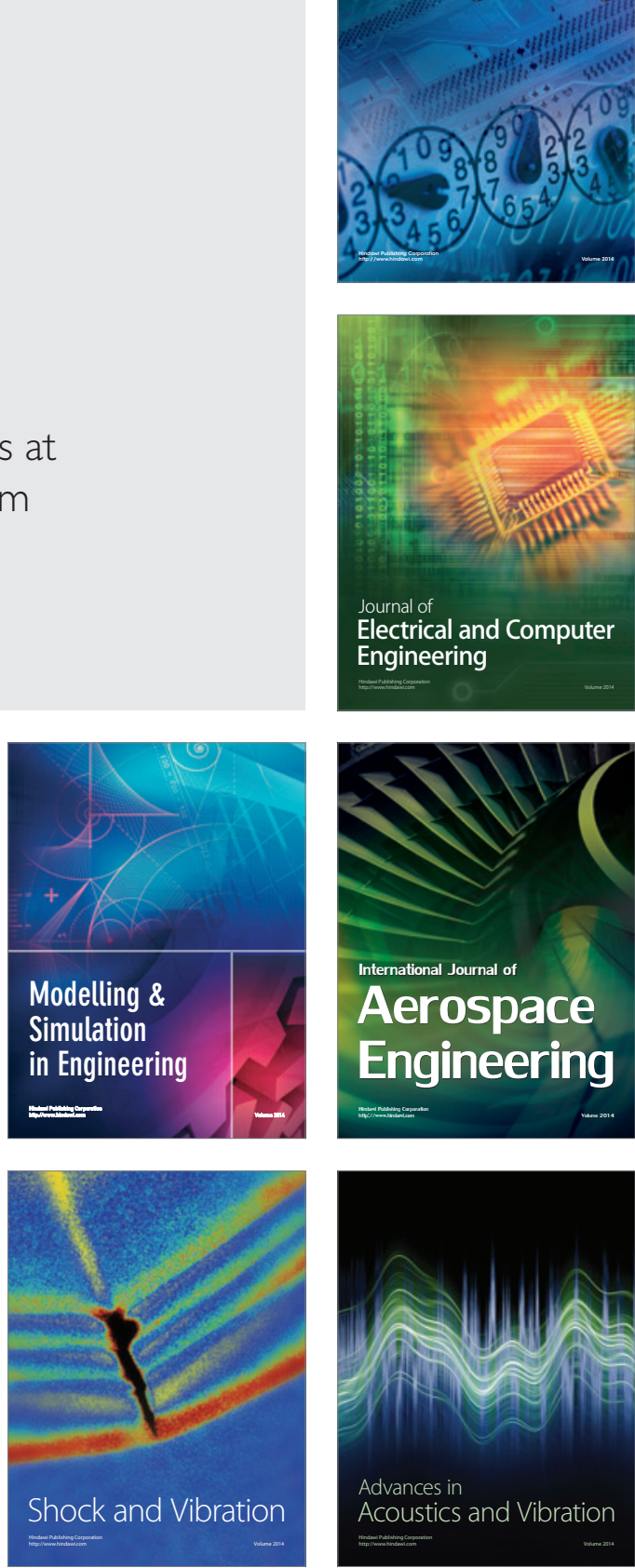